\title{
Sexual differences in spectral sensitivity and wing colouration of 13 species of Japanese Thecline butterflies (Lepidoptera: Lycaenidae)
}

\author{
MichIO IMAFUKU \\ Section of Biological Science, Graduate School of Science, Kyoto University, Sakyo, Kyoto, 606-8502 Japan; \\ e-mail: imafuku@kyoto.zaq.ne.jp
}

Key words. Theclini, Lycaenidae, Lepidoptera, wing colour, spectral reflectance, sexual dimorphism, spectral sensitivity, electroretinography

\begin{abstract}
The correlation between dorsal wing colours and spectral sensitivity of the compound eyes of 13 species of thecline butterflies, consisting of 8 sexually monomorphic and 5 dimorphic species, was investigated. Spectral reflectance of the dorsal surfaces of the wings was measured using a spectrophotometer and spectral sensitivities using electroretinography. All 13 species examined showed a common basic pattern of spectral sensitivity with a primary peak at a wavelength of 440-460 nm. Detailed analyses of the deviations in sensitivity from the basic pattern revealed a correlation in monomorphic species with conspicuous wing hues, especially in males.
\end{abstract}

\section{INTRODUCTION}

Butterflies have the most conspicuous and varied wing colours of all insects. This colouration plays a role in interspecific communication, such as aposematism (Benson, 1972), mimicry (Uésugi, 1996) and as an isolating mechanism (Meyer-Rochow, 1991).

As for intra-specific communication, males are known to respond to wing colours of potential mates in the Nymphalidae (Crane, 1955; Stride, 1956; Magnus, 1958; Silberglied, 1984), Pieridae (Obara, 1970; Rutowski, 1977, 1981; Silberglied \& Taylor, 1978) and Papilionidae (Hidaka \& Yamashita, 1975), with the exception that males of Hipparchia semele (Linnaeus, 1758) show a higher response to darker coloured butterfly models independent of their hues (Tinbergen et al., 1942).

Males of Lycaeides idas (Linnaeus, 1761) distinguish between conspecific and heterospecific females by the size of the black spots scattered over the ventral surface of their wings (Fordyce et al., 2002). Males of Polyommatus icarus (Rottemburg, 1775) prefer females in which the UV-light reflection from the circumference of black spots is suppressed (Knüttel \& Fiedler, 2001). In Heliconius melpomene (Linnaeus, 1758), males of a Panamanian subspecies, rosina Boisduval, 1870, court more intensively paper models of female with the wing colour pattern characteristic of this subspecies than those with the pattern characteristic of a French Guianan subspecies, melpomene (Jiggins et al., 2001). In H. cydno Doubleday, 1874, mates are recognized by the polarized UV-light reflected from the dorsal surface of the wings (Sweeney et al., 2003).

Wing colours are also important in male-male interactions. In Papilio polyxenes Fabricius, 1775, males recognize and fight males with typical yellow wings for less time than those with modified black wings (Lederhouse \& Scriber, 1996).
In addition, females also respond to male colours. Females of Colias eurytheme Boisduval, 1852 recognize conspecific males by the UV-light, rather than the visible light, reflected from the dorsal surface of the wings (Silberglied \& Taylor, 1978). In Pieris protodice Boisdual \& Le Conte, 1830 , females stay longer near butterfly models with UV-light absorbing wings, which simulate those of their own males (Rutowski, 1981). Papilio glaucus Linnaeus, 1758 females solicit males with typical yellow wings more than those with wings painted black (Krebs \& West, 1988). In Bicyclus anynana, (Butler, 1879) females prefer males with large eyespots on the dorsal surface of their wings (Breuker \& Brakefield, 2002) or those with eyespots with a medium-sized white pupil (Robertson \& Monteiro, 2005).

The fact that males and females respond to wing colours of conspecific individuals suggests a correlation between wing colours and spectral sensitivity of their eyes. Each of three species of Heliconius shows spectral sensitivity peaks at wavelength of around 380, 460 and $560 \mathrm{~nm}$ (Struwe, 1972), and the ratio of sensitivity at 560 to that at 380 is highest in H. erato (Linnaeus, 1764) with red forewing bands, intermediate in H. numata (Cramer, 1780 ) with orange and yellow markings on its wings and lowest in H. sara (Fabricius, 1793) with yellow forewing bands. The spectral response curve of Heliconius erato shows a sensitivity maximum at $620 \mathrm{~nm}$ (red), whereas that of Morpho peleides Kollar, 1850, with iridescent blue-ultraviolet wings, is at $485 \mathrm{~nm}$ (blue) (Swihart, 1967). In Pieris rapae (Linnaeus, 1758), which is sexually dimorphic in terms of wing colours, spectral sensitivity of males differs from that of females, probably to facilitate effective discrimination of sexual partners (Arikawa et al., 2005). The UV-signals produced by females of Arctic Pieris napi (Linnaeus, 1758) are stronger than those produced by females of the same species that occur 
TABLE 1. Numbers of specimens used to measure the colour of the wings and spectral sensitivity of the compound eyes of the 13 species of butterfly included in this study.

\begin{tabular}{|c|c|c|c|c|}
\hline \multirow{2}{*}{ Code $^{a}$} & \multirow{2}{*}{ Species name } & \multicolumn{2}{|c|}{ No. specimens } & \multirow{2}{*}{ Collection site $^{b}$} \\
\hline & & Wing colour & Sensitivity & \\
\hline AA & Antigius attilia (Bremer, 1861) & $6 \mathrm{M} 6 \mathrm{~F}$ & $14 \mathrm{M}, 15 \mathrm{~F}$ & 7,9 \\
\hline $\mathrm{AB}$ & A. butleri (Fenton, 1882) & $6 \mathrm{M} 5 \mathrm{~F}$ & $12 \mathrm{M} 12 \mathrm{~F}$ & 1,12 \\
\hline $\mathrm{AE}$ & Araragi enthea (Janson, 1877) & $7 \mathrm{M} 5 \mathrm{~F}$ & $12 \mathrm{M} 12 \mathrm{~F}$ & 4,5 \\
\hline $\mathrm{JL}$ & Japonica lutea (Hewitson, 1865) & $6 \mathrm{M} 6 \mathrm{~F}$ & $12 \mathrm{M} 12 \mathrm{~F}$ & 8,9 \\
\hline JS & J. saepestriata (Hewitson, 1865) & $6 \mathrm{M} 6 \mathrm{~F}$ & $13 \mathrm{M} 11 \mathrm{~F}$ & $2,9,12$ \\
\hline SJ & Shirozua jonasi (Janson, 1877) & $6 \mathrm{M} 6 \mathrm{~F}$ & $12 \mathrm{M} 12 \mathrm{~F}$ & 3,4 \\
\hline AP & Artopoetes preyri (Murray, 1873) & $5 \mathrm{M} 6 \mathrm{~F}$ & $12 \mathrm{M} 12 \mathrm{~F}$ & 5,12 \\
\hline WS & Wagimo signata (Butler, 1882) & $6 \mathrm{M} 6 \mathrm{~F}$ & $11 \mathrm{M} 12 \mathrm{~F}$ & 1 \\
\hline $\mathrm{CA}$ & Chrysozephyrus ataxus (Westwood, 1851) & $5 \mathrm{M}$ & $12 \mathrm{M} 12 \mathrm{~F}$ & 6,10 \\
\hline $\mathrm{FC}$ & Favonius cognatus (Staudinger, 1892) & $10 \mathrm{M}^{\mathrm{c}}$ & $12 \mathrm{M} 12 \mathrm{~F}$ & 12 \\
\hline FU & F. ultramarinus (Fixen, 1887) & $10 \mathrm{M}^{\mathrm{c}}$ & $12 \mathrm{M} 12 \mathrm{~F}$ & 11 \\
\hline FS & F. saphirinus (Staudinger, 1887) & $10 \mathrm{M}^{\mathrm{c}}$ & $11 \mathrm{M} 12 \mathrm{~F}$ & $7,8,9,12$ \\
\hline FY & F. yuasai Shirôzu, 1948 & $1 \mathrm{M}^{\mathrm{c}}$ & $11 \mathrm{M} 11 \mathrm{~F}$ & 2,12 \\
\hline
\end{tabular}

${ }^{\mathrm{a}}$ - a combination of the initials of genus and species names; ${ }^{\mathrm{b}}-1=$ Hirosaki $\mathrm{C}$ (Aomori Pref), $2=$ Hokuto $\mathrm{C}$ (Yamanashi Pref), $3=$ Azumino C, 4 = Suwa C, 5 = Kiso T (Nagano Pref), $6=$ Inabe C (Mie Pref), $7=$ Takashima C, $8=$ Otsu C (Shiga Pref), $9=$ Ibaraki C (Osaka Pref), 10 = Tanabe C (Wakayama Pref), $11=$ Kami T (Hyogo Pref), 12 = Niimi C (Okayama Pref); ${ }^{\mathrm{c}}-$ Data from Imafuku (2008); $\mathrm{M}$ - males; F - females.

at lower latitudes. This indicates that the lower incidence of UV light at high latitudes makes it more difficult for the males there to locate females (Meyer-Rochow \& Järvilehto, 1997). There is thus evidence for a clear correlation between primary peak positions of spectral sensitivity and spectral reflectance from wing surfaces. For the lycaenid species this is particularly true for those belonging to the tribe Arhopalini, Theclinae (Imafuku \& Tsuji, 2008). Visual-pigment spectra and wingreflectance spectra are well matched for the effective discrimination of conspecifics in Lycaena heteronea Boisduval, 1852 with blue wings and L. rubidus (Behr, 1866) with red-orange plus UV wings (Bernard \& Lemington, 1991). There is not, however always a clear correlation as the two lycaenid species, Pseudozizeeria maha (Kollar, 1844) with blue wings and Lycaena phlaeas (Linnaeus, 1761) with red wings, have almost the same pattern of spectral sensitivity with a primary peak at $400 \mathrm{~nm}$ (Eguchi et al., 1982). On the basis of an intensive survey of numerous publications on phylogenetic and molecular analyses, Briscoe \& Chittka (2001) infer that UV-blue-green trichromacy is a basic pattern for all pterygote insects, and stress the importance of approaching this problem from phylogenetic and adaptive points of view.

In Japan, there are 25 species of butterfly belonging to lycaenid tribe Theclini, which have a great variety of different wing colours and include both sexually mono- and dimorphic species. In this study, the colours of the wings and spectral sensitivities of the compound eyes of 13 species were studied. The results reveal significant correlations in monomorphic species but not in dimorphic species.

\section{MATERIAL AND METHODS}

\section{Butterflies}

The spectral sensitivity of the compound eyes of thirteen species of butterflies belonging to the tribe Theclini, Theclinae, Lycaenidae were determined (Table 1). Their wing colours were also determined, except those of the genus Favonius for which data obtained previously (Imafuku, 2008) was used.

Specimens used for the wing colour measurements were collected from June to August in 2001 to 2007, and those for the spectral sensitivity measurement in the same period in 2006, just prior to the measurement. Collection sites and number of specimens examined are shown in Table 1. In this paper, each species has the species code shown in the column on the left hand side of this table.

\section{Wing colours}

For measuring the spectra of the light reflected from the dorsal surface of the wings, a $10 \times 15 \mathrm{~mm}$ piece of the central part or bluish part of the wings of WS and AP was cut out and placed on the stage of a spectrophotometer (Shimadzu, UV-240). The measured range was from 200 to $700 \mathrm{~nm}$, at 10 $\mathrm{nm}$ intervals. The fore wings were used in all species other than Chrysozephyrus and Favonius spp. for which the hind wings with a higher reflectance were used. In the species belonging to these two genera, the colour is dependant on the micro structure of the wing scales (Imafuku et al., 2012) reflecting the different intensities of light in different directions, which is why the specimen was placed on the stage of the spectrophotometer at an angle of $45^{\circ}$, i.e., to obtain maximum reflectance (Imafuku et al., 2002b). On the stage of the spectrophotometer the incident light was applied to the scale surface normally (at a right angle) and the light reflected from a circular area of $3 \mathrm{~mm}$ in diameter was measured. Reflectance was determined as relative to that of a standard reference, namely barium sulphate.

\section{Spectral sensitivity}

For the spectral sensitivity measurements, a specimen whose wings and appendages had been removed was fixed on a stage in a dark Faraday cage, so that one of the compound eyes, usu- 


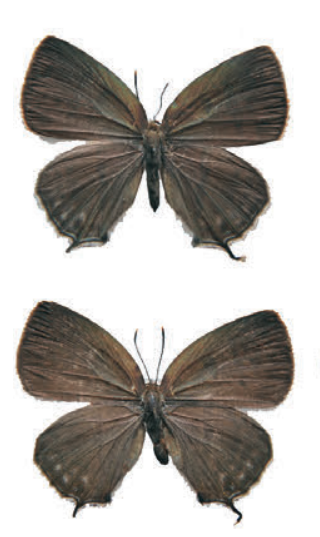

$\mathrm{AA}$
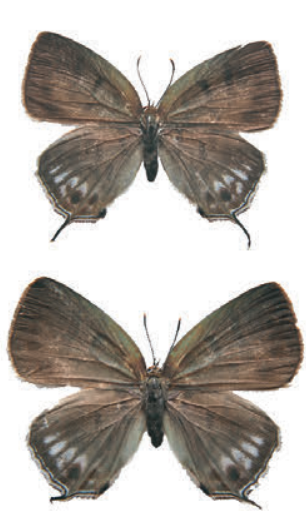

$\mathrm{AB}$
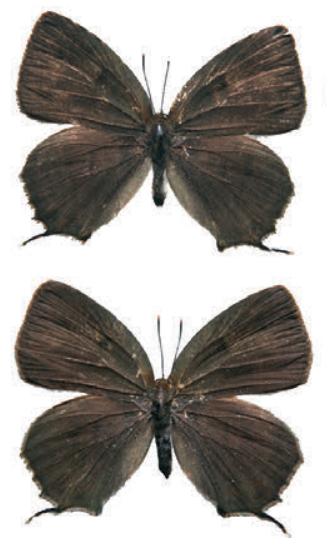

$\mathrm{AE}$
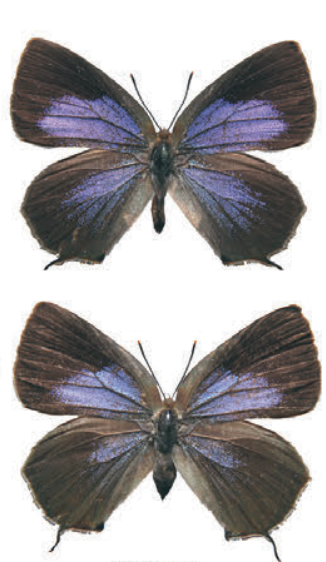

WS
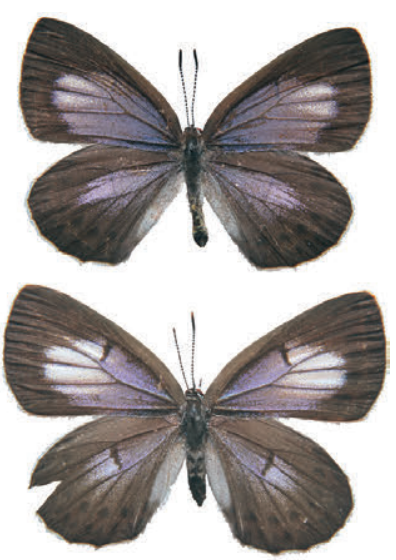

AP
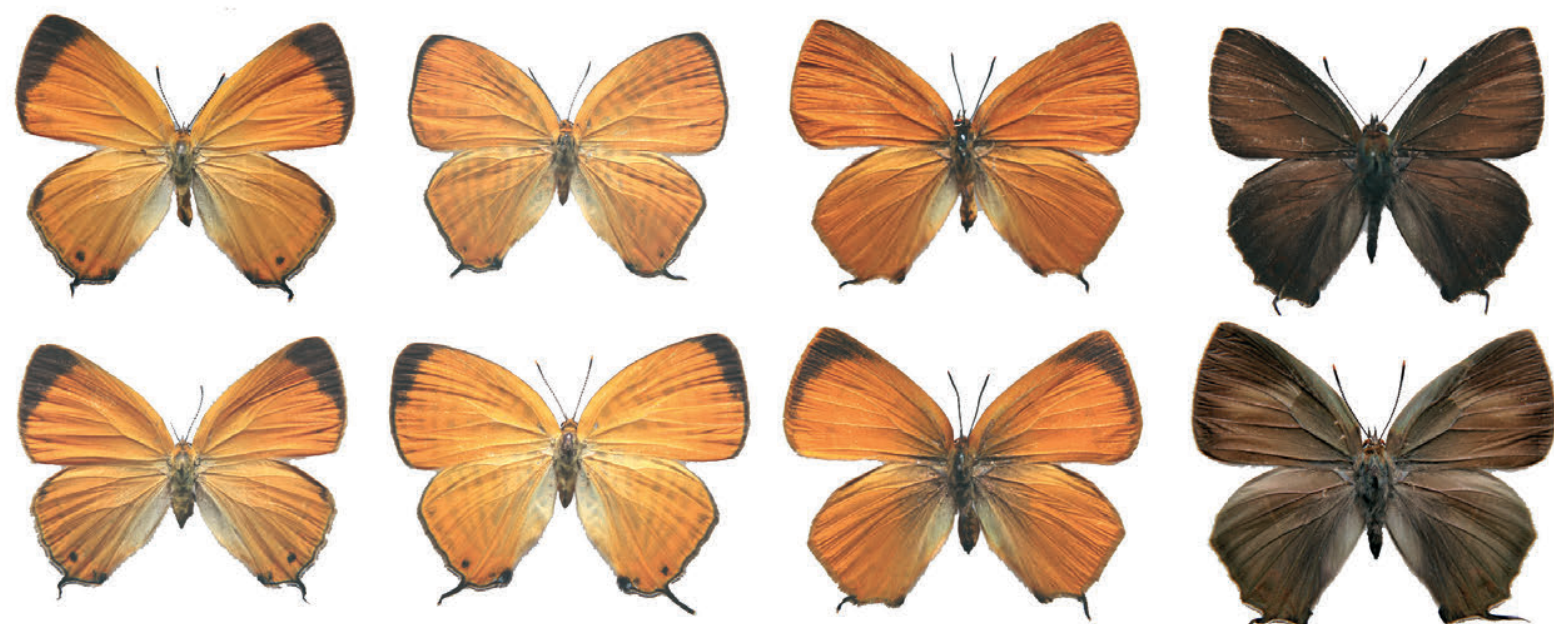

JS

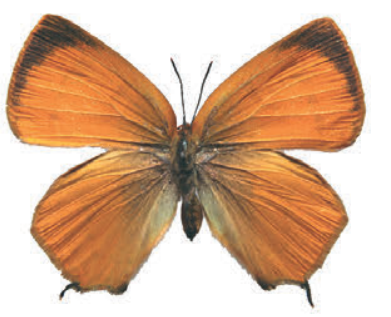

SJ

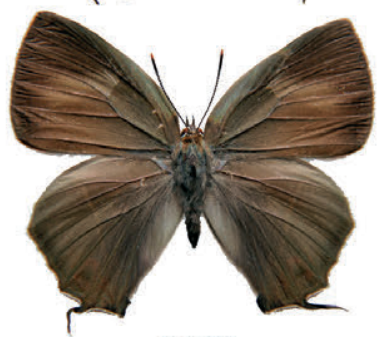

FY

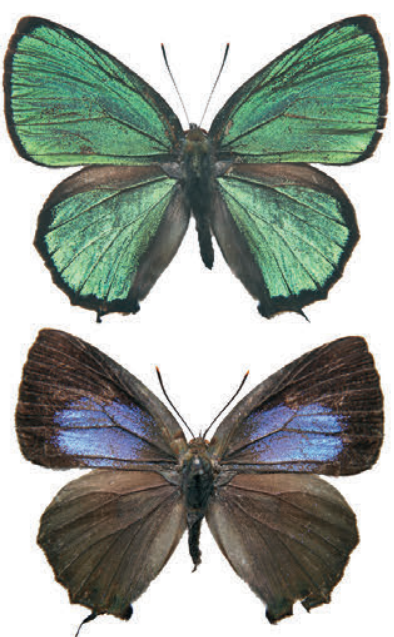

CA

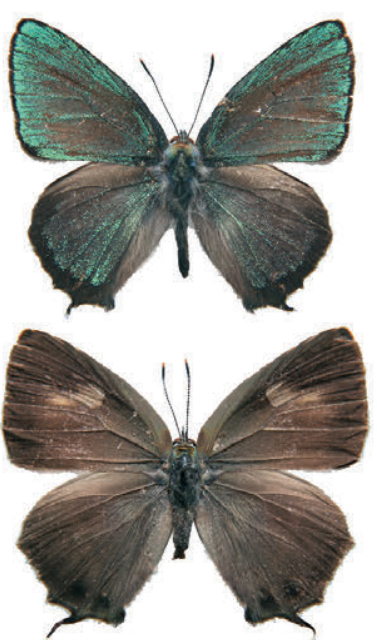

FC

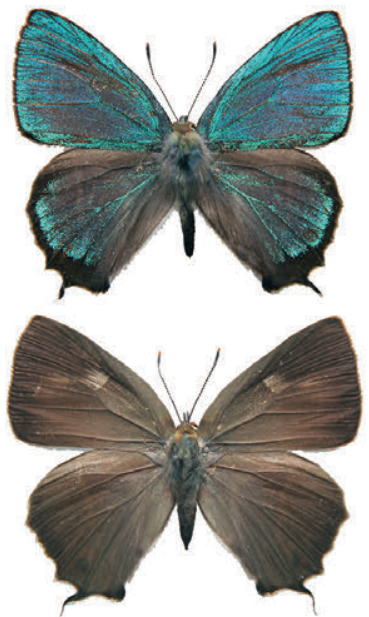

FU
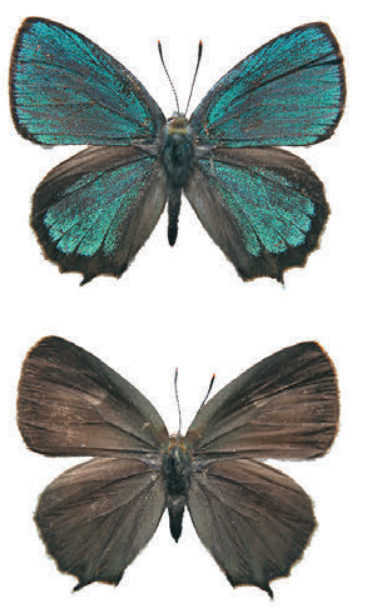

FS

Fig. 1. Dorsal views of 13 species of butterflies belonging to the tribe Theclini. Species codes (see Table 1) are provided below each species, which are arranged with males above and females below.

ally the right eye, faced upwards. The eye was pierced at the centre with a fine needle to make a hole through which one end of the inverted U-shaped active tungsten electrode (M.T. Giken) was inserted to a depth of $250-400 \mu \mathrm{m}$, depending on the size of the head (the thickness of the retina at the centre was $280-500$ $\mu \mathrm{m}$, determined by sectioning). The indifferent tungsten electrode was inserted into the head at a site other than the compound eyes. The eye to be tested was centred in the opening (diameter $1 \mathrm{~cm}$ ) of the integrating sphere (diameter $5 \mathrm{~cm}$ ) lined with a sheet of barium sulphate powder (Sanso), so that the 


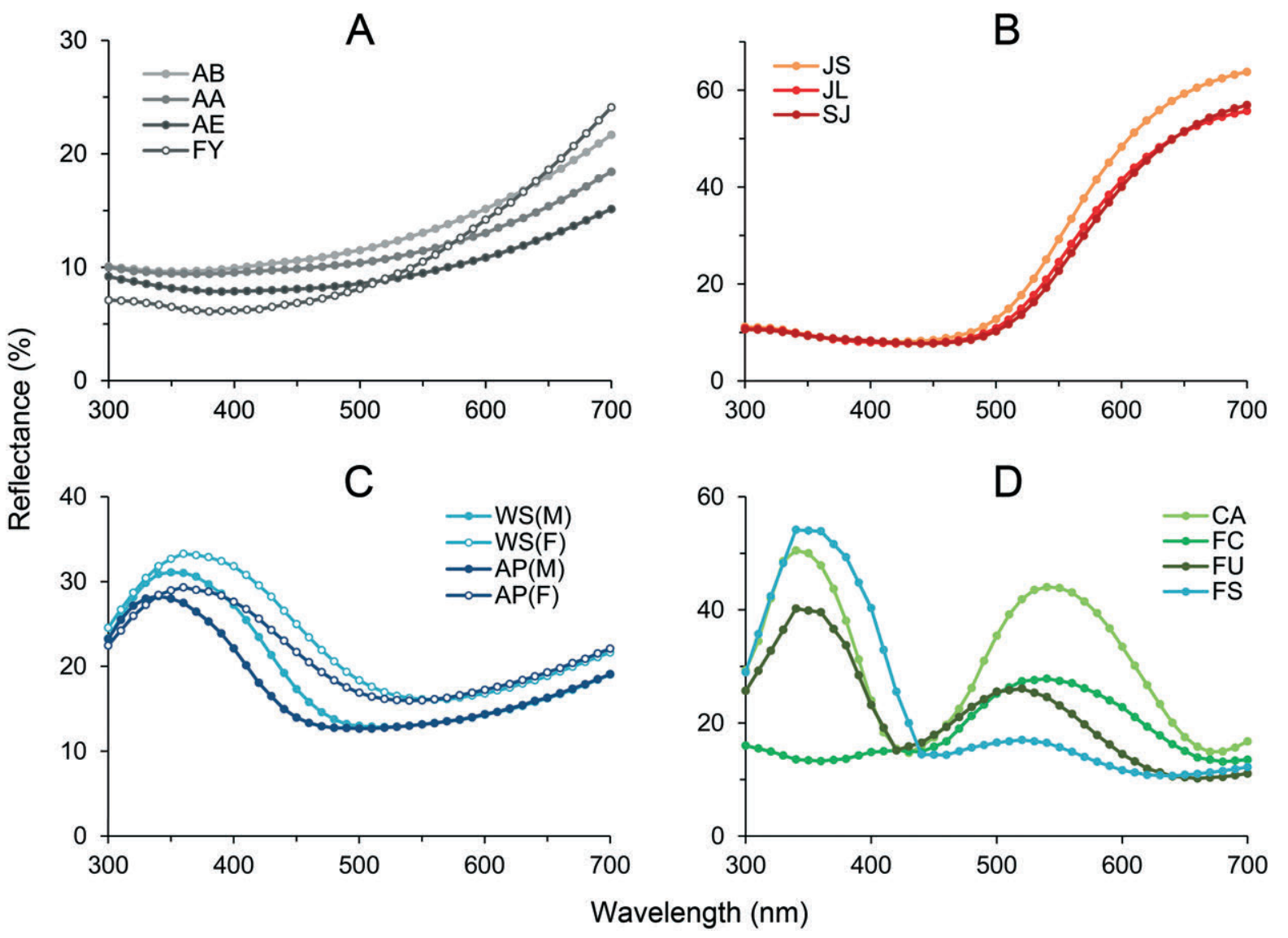

Fig. 2. Reflectance spectra recorded for 13 species of butterflies belonging to the tribe Theclini. A - black species; B - orange species; $\mathrm{C}$ - blue species, with that of the two sexes presented separately $(\mathrm{M}=$ male, $\mathrm{F}=$ female $)$; $\mathrm{D}$ - males of four dimorphic species. For species codes see Table 1 .

hemispherical light distribution existing in the opening stimulated the whole eye. After at least 10 min of dark adaptation, the eye was stimulated with a series of monochromatic flashes $(60$ $\mathrm{ms}$ ) of light of 300-700 nm wave lengths at intervals of $20 \mathrm{~nm}$ in turn with an inter-stimulus interval of $3.5 \mathrm{~s}$, firstly from short to long wave lengths and then in the reverse order. Responses from both processes were averaged. The light intensity of the stimulation light was $1.4 \times 10^{12}$ photons $/ \mathrm{cm}^{2} / \mathrm{s}$.

The response-stimulus intensity $(\mathrm{V}-\log \mathrm{I})$ curve was obtained by taking the response to white light at different light intensities from $8.2 \times 10^{-3} \mathrm{~mW}$ to $2.6 \times 10^{3} \mathrm{~mW}$ at intervals of $0.5 \mathrm{log}$ units, and fitted using a least square optimization method to the Naka-Rushton function, $\mathrm{V}=\mathrm{V}_{\max } \mathrm{I}^{\mathrm{n}} /\left(\mathrm{I}^{\mathrm{n}}+\mathrm{K}^{\mathrm{n}}\right)$, where $\mathrm{V}$ is the response amplitude, $\mathrm{V}_{\max }$ is the maximum response amplitude, $\mathrm{n}$ represents the slope and $\mathrm{K}$ the intensity for the half maximum response (Eguchi \& Horikoshi, 1984). The effective intensities $\mathrm{I}(\mathrm{V})$ of test stimuli evoking response amplitude were then estimated using the inverse function, $\mathrm{I}(\mathrm{V})=\mathrm{K}\left[\mathrm{V} /\left(\mathrm{V}_{\max }-\mathrm{V}\right)\right]^{1 / \mathrm{n}}$ (Pirih et al., 2010). The converted sensitivity curve was normalized to the maximum sensitivity set as one and expressed as relative sensitivity at each spectral point. The measurement of spectral response, of $\mathrm{V}-\log \mathrm{I}$ curve and the conversion were made for each individual.

\section{Statistics}

Comparisons of wing colours between species and sexes, and comparisons of spectral sensitivities between sexes were made using Welch's approximate $t$-test (Sokal \& Rohlf, 1997, p. 405). For comparisons of the spectral sensitivities of species, means for each species were compared with a mean for all 13 species using the $t$-test for differences between a single specimen and a sample (Sokal \& Rohlf, 1997, p. 227). The calculations were carried out using JMP, version 5.1 (SAS Institute Inc.).

\section{RESULTS}

\section{Wing colour}

Dorsal views of the13 butterfly species investigated are shown in Fig. 1. The 9 chromatically monomorphic species consisted of three orange (JL, JS and SJ), two blue (WS and AP) and four black species (AA, AB, AE and FY). The males of Favonius yuasai Shirôzu, 1948, FY, which have dark brown wings similar to those of the females, were allocated to the monomorphic group even though taxonomically they belong to the dimorphic genus Favonius in which all other species are dimorphic (Imafuku, 2008).

The four dimorphic species investigated were males with green (CA and FC) or bluish green (FU and FS) wings.

\section{Spectral reflectance}

Reflectance spectra of the 13 species are shown in Fig. 2. Reflectance spectra of the black species showed shallow U-shaped patterns, gradually rising toward longer wavelengths (Fig. 2A). Patterns of three closely related species (AB, AA and AE) were compared by applying parabolic regression lines. The $\mathrm{x}$-coordinate (wavelength) of the vertex was $370 \mathrm{~nm}$ for AB, $394 \mathrm{~nm}$ for AA and 


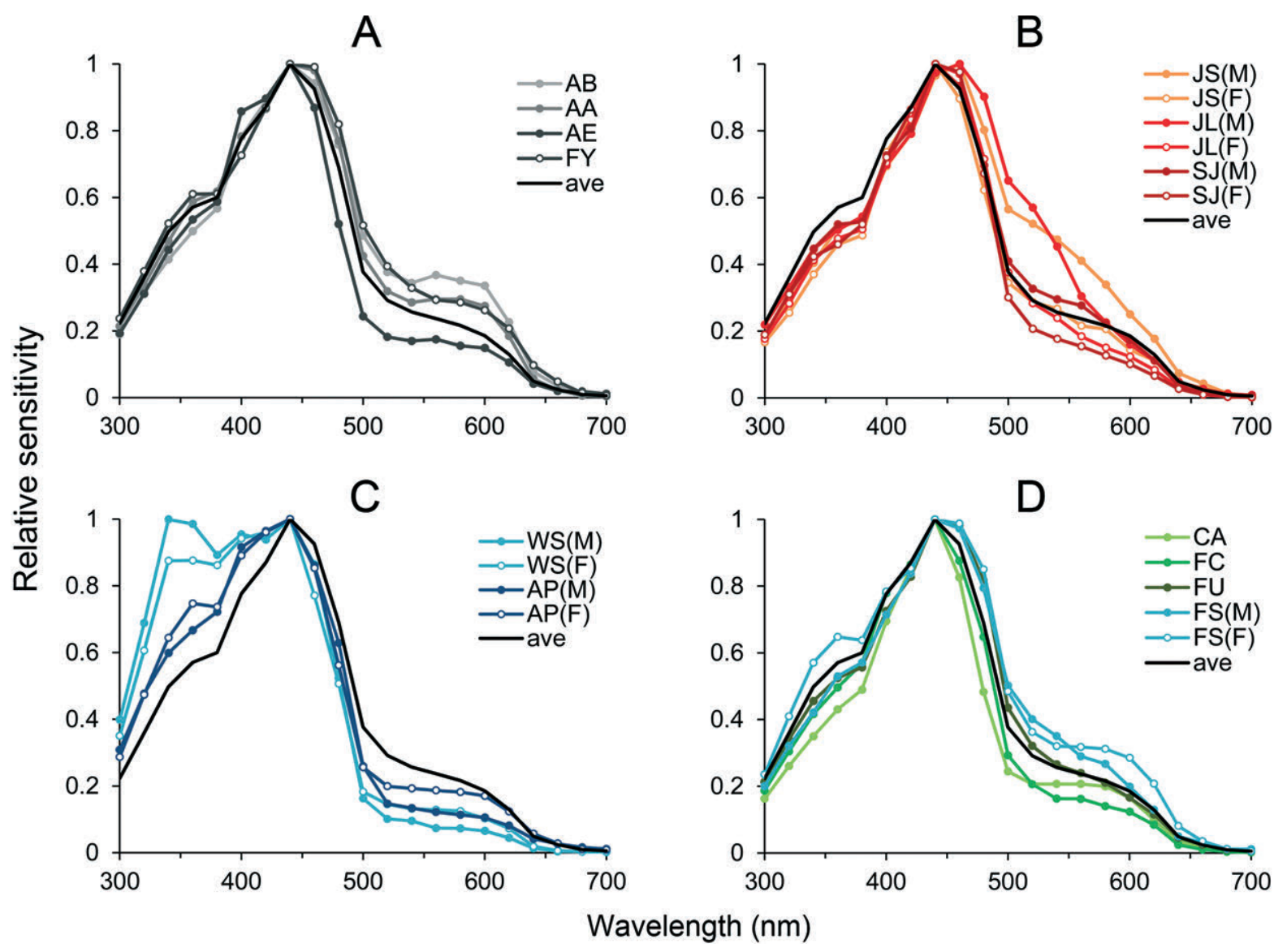

Fig. 3. Sensitivity spectra recorded for 13 species of butterflies belonging to the tribe Theclini. A - black species; B - orange species; C - blue species; D - four dimorphic species. Results for the two sexes are presented for those species for which a difference was detected as shown in Table 2, and for species AP. For species codes see Table 1.

$415 \mathrm{~nm}$ for $\mathrm{AE}(\mathrm{p}<0.01$ for $\mathrm{AB}$ vs. $\mathrm{AA} ; \mathrm{p}<0.01$ for $\mathrm{AA}$ vs. AE). These significant differences explain the difference in the reflectance recorded in the long wavelength regions, which then explains the subtle visually detectable differences in brightness of their wing surfaces, with $\mathrm{AE}$ mostly black, and AB rather "pale" as the Japanese name of this species implies. A weak sexual difference was detected in $\mathrm{AB}(\mathrm{p}=0.045)$ and $\mathrm{AE}(\mathrm{p}=0.043)$.

Orange species showed sigmoid reflectance spectra (Fig. 2B). The differences between species was significant; the inflection point of the sigmoid regression line was $568 \mathrm{~nm}$ for JS, $572 \mathrm{~nm}$ for JL and $579 \mathrm{~nm}$ for SJ ( $\mathrm{p}<$ 0.01 for JS vs. JL; $p<0.01$ for JL vs. SJ). No sexual difference was detected in these species. Differences in the inflection points explain subtle differences in their wing hues; JS slightly yellowish and SJ mostly reddish.

In blue species (Fig. 2C), a sexual difference was detected, with males reflecting more light of shorter wavelengths than females ( $344 \mathrm{~nm}$ in males, $369 \mathrm{~nm}$ in females, $\mathrm{p}<0.01$ for AP; $359 \mathrm{~nm}$ in males, $375 \mathrm{~nm}$ in females, $p<0.01$ for WS). When the results for the sexes were pooled, wings of AP reflected more light of shorter wavelengths than those of WS, but the difference was not significant $(p=0.087)$. Males of AP reflected light of significantly shorter wavelengths than males of WS ( $p<$ 0.01 ), whereas females of these species did not show a significant difference $(p=0.273)$.
Among the four dimorphic species, males of CA and FU showed two peaks in the green and UV regions, and those of FC and FS showed one peak in the green and UV regions, respectively (Fig. 2D). Detailed analyses of the dimorphic species Chrysozephyrus (Imafuku et al., 2002b) and Favonius (Imafuku, 2008) were reported previously.

\section{Spectral sensitivity}

The sensitivity spectra of 13 species showed a similar pattern with a primary peak at $440-460 \mathrm{~nm}$, a shoulder in UV regions and a lower hump in long wavelength regions (Fig. 3), but the sensitivity varied greatly with the species. The sensitivity spectra of species with conspicuous wing hues are illustrated separately for monomorphic (Figs $3 \mathrm{~A}-\mathrm{C}$ ) and dimorphic species (Fig. 3D), along with the averaged spectrum for the 13 species (black lines without markers in the figures).

In monomorphic species, the reflectance spectra of orange species tended to rise in the long wavelength regions (Fig. 3B) and those of blue species in the short wavelength regions (Fig. $3 \mathrm{C}$ ). The average ratio of sensitivity at $540 \mathrm{~nm}$ to that at $360 \mathrm{~nm}$ for each species was compared with the average ratio for all 13 species (Species column in Table 2). Two of the three orange species (JL and JS) showed a significantly higher value and are thus significantly more sensitive to red, while the two 
Table 2. Species and sexual differences in spectral sensitivity recorded for the 13 species of butterfly included in this study. Comparison of the ratio of sensitivity at $540 \mathrm{~nm}$ to that at $360 \mathrm{~nm}$ was made for each species and sex (Species, Male and Female columns), or between sexes (Sexual column). U (means UV sensitive) and R (red sensitive) and indicate that the ratio is significantly smaller or larger than the mean value for the 13 species, respectively. Y indicates a significant difference between the sexes. Single letters mean $p<0.05$, and double letters $\mathrm{p}<0.01$.

\begin{tabular}{ccccc}
\hline Code & Species & Sexual & Male & Female \\
\hline $\begin{array}{l}\text { Monomorphic species } \\
\text { (black) }\end{array}$ & & & \\
AE & UU & & & \\
AA & & & & \\
AB & RR & & & \\
FY & & & & \\
(orange) & & & RR & \\
JL & RR & YY & R & UU \\
JS & RR & YY & RR & \\
SJ & & YY & & \\
(blue) & & & & \\
AP & UU* & & UU** \\
WS & UU & Y & & \\
Dimorphic species & & & & \\
CA & & & & \\
FC & & & & \\
FU & & & & \\
FS & RR & Y & \\
\hline
\end{tabular}

The ratio for males is 0.20 and females 0.25 in $\mathrm{AP}(*)$, and 0.09 for males and 0.15 for females in WS $(* *)$.

blue species showed a significantly lower value and are thus significantly more sensitive to UV.

A sexual difference was found in all three orange species (Sexual column) with males always more sensitive to red (Male and Female columns), including SJ which did not show a specific difference. In the blue species, males of WS showed a significantly higher response to UV light than females, as shown by the ratios in the footnote of Table 2. The same tendency was observed in AP, but the difference was not significant $(\mathrm{p}=0.432)$.

In the dimorphic species, a clear tendency was not observed between wing colours and spectral sensitivity (Fig. 3D). A significant difference from the mean value for all 13 species was sporadically detected in two of the four monomorphic black species and in one of the four dimorphic species (Table 2).

\section{DISCUSSION}

Theclini butterflies consist of sexually monomorphic and dimorphic species. The wing colours of the latter were previously studied (Imafuku et al., 2002b, 2012; Imafuku, 2008).

In the present paper the monomorphic species are tentatively allocated to one of three categories based on wing colours; black (strictly blackish), orange and blue species. The black species tend to show reflectance spectra gradually rising in longer wavelength regions (Fig. 2A). This tendency is also recorded for the dark brown surface of females of dimorphic species (Imafuku et al., 2002b). Melanins are pigments responsible for most of the dark patterning in the body and wings of insects (Ghiradella, 2003), including the wings of the lycaenid Lycaena hippothoe (Linnaeus, 1761) (Karl et al., 2009). The difference in wing colours among the black species seems to be caused by differences in the concentration of melanin in the wing scales.

In the orange species, reflectance rises rapidly around orange and remains high in the red regions (Fig. 2B). This seems to be the general pattern for the orange and red surfaces of butterfly wings, as recorded for the orange marks of Chrysozephyrus smaragdinus (Bremer, 1861) (Imafuku et al., 2002b), and also the red part of the wing surface of several heliconid, nymphalid and papilionid species (Crane, 1954). Orange or red pigments are present in some nymphalid species (Butenandt \& Schäfer, 1962) and Papiliochrome R in Papilio spp. (Umebachi \& Ishizaki, 1983). In lycaenids, there is a large concentration of flavonoids in the sub-marginal orange lunules of the wings of Polyommatus bellargus (Rottemburg, 1775) (Geuder et al., 1997). A 3-hydroxyanthranilic acid derivative, which is derived from tryptophan, is found in the orange scales of Lycaena phlaeas (Umebachi, 1982).

Reflectance spectra of the blue species examined showed a single peak in the short wave length regions, with males reflecting light of shorter wave lengths than females. The same has been recorded for two related thecline species (Imafuku et al., 2002a). Concerning blue pigments, there is a sarpedobilin belonging to a class of tetrapyrroles in the wing membrane of the papilionids Graphium sarpedon (Linnaeus, 1758) (Choussy et al., 1973) and G. weiskei (Ribbe, 1900) (Barbier, 1983). In lycaenids, on the other hand, the blue colour is the consequence of the three dimensional architecture of the wing scales. A bright blue colour of the whole dorsal surface of the wings is produced by a fully ordered three dimensional structure in Cyanophrys remus (Hewitson, 1868) (Kertész et al., 2006) and a multilayered structure in Albulina metallica (C. \& R. Felder, 1865) (Biró et al., 2007). Reflectance spectra of these species are similar to those of the blue species investigated here. The hue of the latter species changed with the angle of observation (unpubl. data), indicating that they are structural colours. Spatial reflectance characteristics of wing scales with a multilayer structure have been investigated in 11 lycaenid, including 7 thecline, species (Wilts et al., 2009).

The compound eyes of butterflies perceive light at wave lengths between 300 and $700 \mathrm{~nm}$ (Arikawa et al., 1987; Imafuku et al., 2007; Imafuku \& Tsuji, 2008). For this wide range of perception, there are 5 types of visual pigments in Paplio xuthus Linnaeus, 1767 (Arikawa et al., 1987) and 4 in two species of Lycaena (Bernard \& Lemington, 1991). The spectral sensitivity pattern of the 13 species studied indicates the presence of at least 3 visual pigments.

The wavelengths butterflies respond most to tend to differ between taxonomic groups; papilionids are most sensitive to violet or UV, nymphalids to green or UV and 
lycaenids between violet and UV (Eguchi et al., 1982). In some species of lycaenids, however, spectral sensitivity to some extent corresponds to wing colours, as mentioned in the Introduction. The 13 theclini species studied have a common basic pattern, which accords with the findings of Eguchi et al. When the minor differences from the basic pattern are considered, however, there are small but significant differences in the sensory characteristics of monomorphic species, which tend to be associated with the differences in their wing colours. Such associations are most marked in males. This indicates that males of the monomorphic species may use visual cues to recognize their mates.

On the other hand, there was no correlation between wing colours and spectral sensitivity in the dimorphic species; males of species with bluish green wings (FS and FU) did not show a specifically higher sensitivity to shorter wave lengths and the sensitivity spectrum of species with green wings (CA and FC) was the average one. Thus, the green and blue colours of these dimorphic species may not signal information to conspecifics. Wing colours of males of the dimorphic species are structural colours (Imafuku et al., 2012) and reflect very strong light. Thus, it may be that the on/off flashing of strong light reflected from flapping wings, or polarized light associated with structural colour (Sweeney et al., 2003) conveys significant information to conspecifics. The wing colours of the dimorphic species were those of males not females. Thus, colour perception by these dimorphic species may be related to female wing colours. The colours of the wings of females of many dimorphic species are dark brown and those of CA are those due to brilliant blue scales whose reflectance peak is located at $400 \mathrm{~nm}$ (Imafuku et al., 2002b), which is near the primary peak position of $440-460 \mathrm{~nm}$ of the spectral sensitivity. These facts indicate that it is not necessary to modify the basic pattern of spectral sensitivity in dimorphic species. Related to this problem is the spectral sensitivity of dimorphic Chrysozephyrus smaragdinus, females of which have a large orange patch on the dorsal surface of the fore wings (Imafuku et al., 2002b). Apart from wing colours, ecological factors such as finding of larval food plants by females (Bernard \& Lemington, 1991) and predator avoidance may also affect spectral sensitivity of lycaenid species.

The ERG method adopted here simply records sensory information at the retinal level, far from the brain at which real perception occurs. Examination of behaviour that is more closely connected to the perception process is needed before a conclusion can be drawn.

ACKNOWLEDGEMENTS. I thank anonymous referees for carefully checking the manuscript and their suggestions for improving the manuscript.

\section{REFERENCES}

Arikawa K., Inokuma K. \& Eguchi E. 1987: Pentachromatic visual system in a butterfly. - Naturwissenschaften 74: 297-298.
Arikawa K., Wakakuwa M., Qiu X., Kurasawa M. \& Stavenga D.G. 2005: Sexual dimorphism of short-wavelength photoreceptors in the small white butterfly, Pieris rapae crucivora. - J. Neurosci. 25: 5935-5942.

BARBIER M. 1983: The pigments of Papilio graphium weiskei: Sarpedobilin and ommin responsible for a unique pattern in a butterfly wing membrane. - Comp. Biochem. Physiol. (B) 76: $57-59$.

Benson W.W. 1972: Natural selection for Müllerian mimicry in Heliconius erato in Costa Rica. - Science 176: 936-939.

Bernard G.D. \& Remington C.L. 1991: Color vision in Lycaena butterflies: spectral tuning of receptor arrays in relation to behavioral ecology. - Proc. Natl. Acad. Sci. 88: 2783-2787.

Biró L.P., Kertész K., Vértesy Z., Márk G.I., BÁlint Zs., Lousse V. \& Vigneron J.-P. 2007: Living photonic crystals: Butterfly scales - Nanostructure and optical properties. Mater. Sci. Eng. (C) 27: 941-946.

BReUKer C.J. \& BRAKefield P.M. 2002: Female choice depends on size but not symmetry of dorsal eyespots in the butterfly Bicyclus anynana. - Proc. R. Soc. Lond. (B) 269: 1233-1239.

BRISCOE A.D. \& ChITTKA L. 2001: The evolution of color vision in insects. - Annu. Rev. Entomol. 46: 471-510.

Butenandt A. \& SchäFer W. 1962: Ommochromes. In Gore T.S., Joshi B.S., Sunthankar S.V. \& Tilak B.D. (eds): Recent Progress in the Chemistry of Natural and Synthetic Colouring Matters and Related Fields. Academic Press, New York, pp. 13-33.

Choussy M., Barbier M., Rüdiger W. \& Klose W. 1973: Preliminary report on the neopterobilins, blue-green pigments from Lepidoptera. - Comp. Biochem. Physiol. (B) 44: 47-52.

CRANE J. 1954: Spectral reflectance characteristics of butterflies (Lepidoptera) from Trinidad, B. W. I. - Zoologica 39: 85-115.

CRANE J. 1955: Imaginal behavior of a Trinidad butterfly, Heliconius erato hydara Hewitson, with special reference to the social use of color. - Zoologica 40: 167-196.

Eguchi E. \& Horikoshi T. 1984: Comparison of stimulusresponse (V-log I) functions in five types of lepidopteran compound eyes (46 species ). - J. Comp. Physiol. 154: 3-12.

Eguchi E., Watanabe K., Hariyama T. \& Yamamoto K. 1982: A comparison of electrophysiologically determined spectral responses in 35 species of Lepidoptera. - J. Insect Physiol. 28: $675-682$.

Fordyce J.A., Nice C.C., Forister M.L. \& Shapiro A.M. 2002: The significance of wing pattern diversity in the Lycaenidae: mate discrimination by two recently diverged species. $-J$. Evol. Biol. 15: 871-879.

Geuder M., Wray V., Fiedler K. \& Proksch P. 1997: Sequestration and metabolism of host-plant flavonoids by the lycaenid butterfly Polyommatus bellargus. - J. Chem. Ecol. 23: $1361-1372$.

Ghiradella H. 2003: Coloration. In Resh V.H. \& Cardé R.T. (eds): Encyclopedia of Insects. Academic Press, London, pp. 244-251.

Hidaka T. \& Yamashita K. 1975: Wing color pattern as the releaser of mating behavior in the swallowtail butterfly, Papilio xuthus L. (Lepidoptera: Papilionidae). - Appl. Entomol. Zool. 10: 263-267.

IMAFUKU M. 2008: Variation in UV light reflected from the wings of Favonius and Quercusia butterflies. - Entomol. Sci. 11: $75-80$.

IMAFuKu M. \& TsuJI K. 2008: Spectral sensitivity and wing colors of Narathura and Panchala species. - J. Insect Physiol. 54: 1511-1515. 
ImAfuKu M., Gotoh S. \& TAKEUChI T. 2002a: Ultraviolet reflection by the male of Narathura bazalus (Lycaenidae). Trans. Lepid. Soc. Japan 53: 197-203.

IMAFUKU M., Hirose Y. \& TAKeUChI T. 2002b: Wing colors of Chrysozephyrus butterflies (Lepidoptera; Lycaenidae): Ultraviolet reflection by males. - Zool. Sci. 19: 175-183.

Imafuku M., Shimizu I., Imai H. \& Shichida Y. 2007: Sexual difference in color sense in a lycaenid butterfly, Narathura japonica. - Zool. Sci. 24: 611-613.

ImAfuku M., Kubota H.Y. \& Inouye K. 2012: Wing colors based on arrangement of the multilayer structure of wing scales in lycaenid butterflies (Insecta: Lepidoptera). - Entomol. Sci. 15: 400-407.

Jiggins C.D., Naisbit R.E., Coe R.L. \& Mallet J. 2001: Reproductive isolation caused by colour pattern mimicry. - Nature 411: 302-305.

KARL I., GeISTER T.L. \& Fischer K. 2009: Intraspecific variation in wing and pupal melanization in copper butterflies (Lepidoptera: Lycaenidae). — Biol. J. Linn. Soc. 98: 301-312.

Kertész K., Bálint Z., Vértesy Z., Márk G.I., Lousse V., Vigneron J.P., Rassart M. \& Biró L.P. 2006: Gleaming and dull surface textures from photonic-crystal-type nanostructures in the butterfly Cyanophrys remus. - Phys. Rev. E 74: 021922-1-15.

KNÜTTEL H. \& FIEDLER K. 2001: Host-plant-derived variation in ultraviolet wing patterns influences mate selection by male butterflies. - J. Exp. Biol. 204: 2447-2459.

Krebs R.A. \& West D.A. 1988: Female mate preference and the evolution of female-limited Batesian mimicry. - Evolution 42: 1101-1104.

Lederhouse R.C. \& Scriber J.M. 1996: Intrasexual selection constrains the evolution of the dorsal color pattern of male black swallowtail butterflies, Papilio polyxenes. - Evolution 50: 717-722.

Magnus D. 1958: Experimentelle Untersuchungen zur Bionomie und Ethologie des Kaisermantels Argynnis paphia L. (Lep. Nymph.) I. Über optische Auslöser von Anfliegereaktionen und ihre Bedeutung für das Sichfinden der Geschlechter. - Z. Tierpsychol. 15: 397-426.

MeYer-Rochow V.B. 1991: Differences in ultraviolet wing patterns in the New Zealand lycaenid butterflies Lycaena salustius, $L$. rauparaha and $L$. feredayi as a likely isolating mechanism. - J. R. Soc. N. Z. 21: 169-177.

MeYer-Rochow V.B. \& JÄRvILEHTO M. 1997: Ultraviolet colours in Pieris napi from Northern and Southern Finland: Arctic females are the brightest! - Naturwissenschaften 84: $165-168$.

OBARA Y. 1970: Studies on the mating behavior of the white cabbage butterfly, Pieris rapae crucivora Boisduval. III. Near-ultra-violet reflection as the signal of intraspecific communication. - Z. Vergl. Physiol. 69: 99-116.
Pirih P., Arikawa K. \& Stavenga D.G. 2010: An expanded set of photoreceptors in the Eastern Pale Clouded Yellow butterfly, Colias erate. - J. Comp. Physiol. 196: 501-517.

Robertson K.A. \& Monteiro A. 2005: Female Bicyclus anynana butterflies choose males on the basis of their dorsal UVreflective eyespot pupils. - Proc. R. Soc. (B) 272: 1541-1546.

Rutowski R.L. 1977: The use of visual cues in sexual and species discrimination by males of the small sulphur butterfly Eurema lisa (Lepidoptera, Pieridae). - J. Comp. Physiol. 115: $61-74$.

RUTOWSKI R.L. 1981: Sexual discrimination using visual cues in the checkered white butterfly (Pieris protodice). $-Z$. Tierpsychol. 55: 325-334.

SilBeRGLIED R.E. 1984: Visual communication and sexual selection among butterflies. In Vane-Wright R., Ackery P. \& DeVries P. (eds): The Biology of Butterflies. Academic Press, London, pp. 207-223.

SiLBERGLIED R.E. \& TAYLOR O.R. JR. 1978: Ultraviolet reflection and its behavioral role in the courtship of the sulfur butterflies Colias eurytheme and C. philodice (Lepidoptera, Pieridae). - Behav. Ecol. Sociobiol. 3: 203-243.

SOKal R.R. \& Rohlf F.J. 1997: Biometry. 3rd ed. Freeman, New York, $887 \mathrm{pp}$.

STRIDE G.O. 1956: On the courtship behaviour of Hypolimnas misippus L., (Lepidoptera, Nymphalidae), with notes on the mimetic association with Danaus chrysippus L., (Lepidoptera, Danaidae). - Brit. J. Anim. Behav. 4: 52-68.

Struwe G. 1972: Spectral sensitivity of the compound eye in butterflies (Heliconius). - J. Comp. Physiol. 79: 191-196.

Sweeney A., Jiggins C. \& Johnsen S. 2003: Polarized light as a butterfly mating signal. - Nature 423: 31-32.

SwiHart S.L. 1967: Neural adaptations in the visual pathway of certain heliconiine butterflies, and related forms, to variations in wing coloration. - Zoologica 52: 1-14.

Tinbergen N., Meeuse B.J.D., Boerema L.K. \& Varossieau W.W. 1942: Die Balz des Samtfalters, Eumenis (= Satyrus) semele (L.). - Z. Vergl. Physiol. 5: 182-226.

UÉSUGI K. 1996: The adaptive significance of Batesian mimicry in the swallowtail butterfly, Papilio polytes (Insecta, Papilionidae): associative learning in a predator. - Ethology 102: $762-775$.

UMEBACHI Y. 1982: Chemical properties of the orange pigment of Lycaena phlaeas (Lepidoptera). - Comp. Biochem. Physiol. (B) 73: 235-238.

UMEBACHI Y. \& IsHIZAKI Y. 1983: Beta-alanine and dopamine in the reddish brown scales of Papilio butterflies. - Sci. Rep. Kanazawa Univ. 28: 59-67.

Wilts D.B., Leertouwer H.L. \& Stavenga D.G. 2009: Imaging scatterometry and microspectrophotometry of lycaenid butterfly wing scales with perforated multilayers. $-J$. R. Soc. Interface 6: S185-S192.

Received August 3, 2012; revised and accepted February 11, 2013 